\title{
Constituintes químicos e estudos toxicológicos do óleo essencial extraído das folhas de Citrus limon Burn (Rutaceae)
}

CAMPELO, L.M.L.'; SÁ, C.G. ${ }^{1}$; FEITOSA, C.M. ${ }^{1,2}$; SOUSA, G.F.'; FREITAS, R.M. ${ }^{1, *}$

${ }^{1}$ Laboratório de Pesquisa em Neuroquímica Experimental do Programa de Pós-graduação em Ciências Farmacêuticas, Centro de Ciências da Saúde, Campus Ministro Petrônio Portela, CEP: 64.049-550, TeresinaBrasil *rivelilson@pq.cnpq.br ${ }^{2}$ Departamento de Química, Centro de Ciências da Natureza, Campus Ministro Petrônio Portela, CEP: 64.049-550, Teresina-Brasil

RESUMO: A caracterização química do óleo essencial de folhas de Citrus limon (Rutaceae) resultou na identificação de mistura de monoterpenos (limoneno, linalol, cis-óxido de limoneno, trans-óxido de limoneno, citronelal, neral, geranial, nerol e acetato de geranil). As estruturas dos compostos do óleo essencial foram identificadas por GC/MS, por comparação com dados da literatura. Os efeitos da administração crônica oral do óleo essencial de folhas de Citrus limon foram investigados sobre parâmetros bioquímicos e hematológicos em camundongos Swiss machos. Os animais ( $n=10 /$ grupo) foram tratados por via oral diariamente durante 30 dias com óleo essencial de folhas de Citrus limon, nas doses de 50,100 ou $150 \mathrm{mg} \mathrm{kg}^{-1}$ de massa corporal e os parâmetros bioquímicos e hematológicos avaliados. $\mathrm{O}$ tratamento não causou nenhuma morte ou toxicidade nos animais. A administração do óleo essencial não alterou os parâmetros bioquímicos e hematológicos e a massa dos órgãos, exceto por diminuição de 21 e $11 \%$ em uréia e ácido úrico, respectivamente, e $9 \%$, nos níveis plasmáticos de aspartato transaminase (AST). Para os parâmetros hematológicos, houve pequenas mudanças nas contagens de neutrófilos, linfócitos, eosinófilos e monócitos, mas estes não foram diferentes dos valores de referência. Além disso, houve diminuição significativa nos triglicerídeos detectado nos animais tratados com dose de $150 \mathrm{mg} \mathrm{kg}^{-1}$ de óleo essencial. Em conclusão, a administração crônica de óleo essencial não induziu nenhum efeito de risco na maioria dos parâmetros bioquímicos e hematológicos estudados em camundongos Swiss machos. No entanto, a diminuição dos níveis de uréia e ácido úrico em doses elevadas, sugere um possível efeito de insuficiência renal e aumento no teor de AST, sugerindo possível sobrecarga hepática que deve ser investigada com mais detalhe.

Palavras-chave: Citrus limon, óleo essencial, tratamento crônico, hematologia, bioquímica

ABSTRACT: Chemical constituents and toxicological studies of the essential oil extracted from Citrus limon Burn (Rutaceae). The chemical characterization of the essential oil of Citrus limon (Rutaceae) leaves resulted in the identification of a mixture of monoterpenes (limonene, linalool, cis-limonene-oxide, trans-limonene-oxide, citronellal, neral, geranial, nerol e geranyl acetate). The structures of the compounds of essential oil were identified by GC/MS by comparison with literature data. The effects of the chronic oral administration of the essential oil of Citrus limon leaves were investigated on biochemical and hematological parameters in male adult Swiss mice. These animals ( $n=10 /$ group) were orally treated daily for 30 days with essential oil of Citrus limon leaves with doses of 50,100 or $150 \mathrm{mg} \mathrm{kg}^{-1}$ body weight and the biochemical and hematological parameters were evaluated. The treatment did not cause any deaths or toxicity in the animals. The administration of essential oil did not change biochemical and hematological parameters and organ weight, except for decreases of 21 and $11 \%$ in blood urea nitrogen and uric acid respectively, and 9\%, in aspatate transaminase (AST) plasma level. For the hematological parameters, there were slight changes in which neutrophil, lymphocytes, eosinophils and monocyte counts were not different from the reference values. In addition, with respect to serum triglyceride a significant decrease was detected in mice treated with a dose of $150 \mathrm{mg} \mathrm{kg}^{-1}$ of essential oil from Citrus limon. In conclusion, the chronic administration of essential oil of Citrus limon leaves did not induce any harzadous effects on most of the biochemical and hematological parameters studied in male adult Swiss mice. However, the 
decrease in the levels in blood urea nitrogen and uric acid in high doses, suggests a possible effect of renal insufficiency and an increase in AST content, which in its turn, suggests a possible hepatic overload which should be investigated in more details.

Keywords: Citrus limon, essential oil, chronic treatment, hematology, biochemistry

\section{INTRODUÇÃO}

A família Rutaceae consiste de cerca de 150 gêneros e 1.600 espécies, distribuídas amplamente em regiões tropicais, subtropicais e temperadas do mundo, sendo mais abundante na América tropical, Sul da África e Austrália. No Brasil, a família está representada por aproximadamente 29 gêneros e 182 espécies, com algumas de importância medicinal, ecológica e econômica (Melo, 2004). O Citrus é um gênero que compreende cerca de 70 espécies de subarbustos e arbustos que podem ser cultivadas ou encontradas espontaneamente na Alemanha, Espanha, México, Venezuela, Cuba, Jamaica, Equador, e no Norte e Nordeste do Brasil (Kuster et al., 2003).

As espécies do gênero Citrus são ricas em flavonóides, óleos voláteis, cumarinas e pectinas (Kuster et al., 2003). A maioria dos compostos flavônicos são heterosídeos de flavanonas (hesperidosídeo, neohesperidosídeo, naringosídeo, eriodictiosídeo). Ocorrem também outros flavonóides, como a diosmina e o rutosídeo (Arriaga, 1990; Bruneton, 1993). O fruto imaturo contém sinefrina e n-metiltiramina (Huang et al., 1995). O óleo volátil da casca do fruto apresenta atividade sedativa, hipnótica, contrastando com o extrato etanólico das folhas, que não apresenta esta atividade (Carvalho-Freitas, 2002). O extrato alcoólico da casca dos frutos mostrou efeito antiespasmódico (Foster et al., 1980). Testes farmacológicos in vitro, com o extrato dos frutos demonstraram potente efeito inibidor contra a atividade do rotavírus (Hyun et al., 2000). O suco dos frutos também apresentou, in vitro, atividade antimicrobiana (Caceres et al., 1987) e devido à presença da sinefrina produziu redução do consumo de alimento e do ganho de massa corporal e reduziu a pressão portal em ratos (Huang et al., 1995; Calapai et al., 1999).

Citrus limon é popularmente conhecido como limoeiro, cujas folhas e frutos são aproveitadas pela medicina popular para fins terapêuticos, essa planta também é conhecida como limão verdadeiro, e é originária da Região Sudeste da Ásia (Penidon \& Silva, 2007). O Citrus limon possui várias ações terapêuticas na medicina popular, como adstringente, antianêmico, antibiótico, antisséptico, antiemético, antidepressivo, antiinflamatório, antiespasmódico, bactericida, antireumático, antidisentérico (Vieira, 1992; Rezende \& Cocco, 2002; Vendruscolo et al.,
2005; Fenner et al., 2006; Agra et al., 2007; Penidon \& Silva, 2007) e ainda para tratamento da febre e da tosse (Liebstein, 1927; De Feo et al., 1992; Gray \& Flatt, 1997).

A extração do óleo essencial da folhas de Citrus limon e análise por CG possibilitaram a identificação de nove monoterpenos (limoneno, linalol, citronelol, neral, nerol, cis-óxido-limoneno, trans-óxido-limoneno, geraniol e acetato de geraniol). Após a extração do óleo essencial foram avaliados os efeitos após administração crônica em parâmetros bioquímicos e hematológicos de camundongos, além do efeito sobre a massa de algumas vísceras.

\section{MATERIAL E MÉTODO}

\section{Material vegetal}

As folhas de Citrus limon para o referido estudo foram coletadas às 8 horas da manhã do mês de Fevereiro de 2010 de hortas medicinais existentes nas proximidades do Campus Senador Helvídio Nunes de Barros da Universidade Federal do Piauí no município de Picos, Piauí. As exsicatas da espécie (Número 26.453) foram depositadas no Herbário Graziella Barroso da Universidade Federal do Piauí. Após a pesquisa de materiais estranhos, a matéria-prima vegetal foi usada para extrair o óleo essencial.

\section{Extração do Óleo Volátil}

O óleo essencial de Citrus limon foi obtido partindo-se de $1.100 \mathrm{~g}$ de folhas frescas trituradas e utilizando-se o sistema de hidrodestilação, em aparelho tipo Clevenger (Matos, 1999) durante o período de quatro horas. O óleo coletado foi subsequentemente seco com sulfato de sódio anidro $\left(\mathrm{Na}_{2} \mathrm{SO}_{4}\right)$ e mantido sob refrigeração até a realização da análise. $O$ rendimento do óleo foi de $0,29 \%$, calculados com base nos volumes de óleo obtido e do peso do material vegetal fresco.

\section{Análise do Óleo Volátil e Identificação dos Constituintes}

A análise dos constituintes voláteis foi realizada em equipamento CG/EM HewlettPackard, Modelo 5971 usando-se coluna capilar não-polar DB-1, de sílica fundida (30 m x 0,25 mm 
i.d., película de $0,25 \mu \mathrm{m}$ ); carreado por gás hélio;

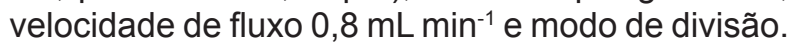
A temperatura do injector e do detector foram $250^{\circ} \mathrm{C}$ e $200^{\circ} \mathrm{C}$, respectivamente. A temperatura da coluna foi programada de $35^{\circ} \mathrm{C}$ para $180^{\circ} \mathrm{C} \mathrm{em} 4^{\circ} \mathrm{C} \mathrm{min}-1$ e em seguida $180^{\circ} \mathrm{C}$ para $250^{\circ} \mathrm{C}$ em $10^{\circ} \mathrm{C} \mathrm{min}{ }^{-1}$. Os espectros de massas foram gravados a partir de $30-450 \mathrm{~m} \mathrm{z}^{-1}$. Componentes individuais foram identificados por correspondência de seus espectros de massa, $70 \mathrm{eV}$, com os da base de dados usando a biblioteca construída através do espectrômetro Wiley e outros dois computadores utilizando índices de retenção como uma pré-seleção (Alencar et al., 1984,1990), bem como por comparação visual da fragmentação padrão com aqueles relatados na literatura (Adams, 2001).

\section{Estudos dos efeitos do óleo essencial de Citrus limon em parâmetros hematológicos e bioquímicos de camundongos}

\section{Animais e Tratamento}

Foram utilizados camundongos Swiss machos com 2 meses de idade e com peso de 25 a $30 \mathrm{~g}$, provenientes do Biotério Central do Centro de Ciências Agrárias da Universidade Federal do Piauí. Os animais receberam água e dieta (Labina ${ }^{\circledR}$ ) ad libitum e foram mantidos sob condições controladas de iluminação (ciclo $12 \mathrm{~h}$ claro/escuro) e temperatura $\left(23 \pm 2^{\circ} \mathrm{C}\right)$. O projeto foi aprovado pelo Comitê de Ética em Experimentação com Animais da Universidade Federal do Piauí.

Quarenta camundongos correspondendo a quatro grupos ( $n=10 /$ grupo) foram tratados durante 30 dias consecutivos, por via oral, com o óleo essencial de Citrus limon nas doses de 50, 100 e 150 $\mathrm{mg} \mathrm{kg}^{-1}$ dissolvido em Tween 80 0,5\% (grupos OECL 50, OECL 100 e OECL 150), Tween 80 0,5\% (grupo Tween 80 ) ou solução salina $0,9 \%$ (grupo controle).

Durante o tratamento, a massa corporal dos animais foi registrada semanalmente e os animais avaliados quanto a sinais clínicos de toxicidade, consumo de água e ração. Ao final do tratamento, os animais foram submetidos a jejum de $12 \mathrm{~h}$ e anestesiados com éter. Em seguida, foi feita à coleta de sangue por rompimento do plexo retroorbital com auxílio de capilar de vidro (Waynforth, 1980). O sangue foi acondicionado em dois tipos de tubo, um com anticoagulante HB (Laborlab ${ }^{\circledR}$ ) para determinação dos parâmetros hematológicos e o outro, sem anticoagulante, para obtenção do soro para avaliação dos parâmetros bioquímicos.

\section{Análise dos parâmetros bioquímicos e hematológicos}

Para análise bioquímica, o material foi centrifugado a $3500 \mathrm{rpm}$ durante 10 minutos e, em seguida, determinados os parâmetros glicose, uréia, creatinina, aspartato aminotransferase (AST), alanina aminotransferase (AST) colesterol total, triglicerídeos, fosfatase alcalina (ALP), bilirrubinas total e direta, proteínas totais e ácido úrico. Os ensaios foram realizados em aparelho automático Labmax 240 com sistemas comerciais da LABTEST $^{\circledR}$.

Os valores para eritrócitos, leucócitos, plaquetas, hemoglobina, hematócrito e os índices hematimétricos volume corpuscular médio (VCM), hemoglobina corpuscular média (HCM) e concentração de hemoglobina corpuscular média ( $\mathrm{CHCM}$ ) foram determinados imediatamente após a coleta através do analisador automático de células hematológicas Advia 120/hematology (Siemens). A contagem diferencial de leucócitos foi realizada em extensões coradas com May-Grünwald-Giemsa. Em cada ensaio, 100 células foram analisadas e contadas.

\section{Análises estatísticas}

Os valores estão expressos como média \pm erro padrão da média (E.P.M.). A diferença entre os grupos foi determinada através da Análise de Variância (ANOVA), seguida, quando detectada diferença, pelo teste $t$ de Student-Newman-Keuls. O nível de significância para rejeição da hipótese de nulidade foi sempre > a $5 \%$.

\section{RESULTADO E DISCUSSÃO}

\section{Resultados do rendimento e identificação da composição química do óleo essencial extraído das folhas de Citrus limon}

Os rendimentos, a composição química e as percentagens relativas dos constituintes encontrados no óleo volátil, da amostra obtida a partir das folhas de Citrus limon, estão apresentados na Tabela 1. O rendimento calculado com base na massa das folhas frescas foi determinado como sendo $0,29 \%$, similar ao óleo volátil obtido com as folhas de Citrus (Tu, 2002).

A identificação de derivados voláteis foi realizada por interpretação automatizada de espectros de massa dos constituintes na amostra de óleo e ainda pelo índice de retenção. Um total de nove derivados, exclusivamente monoterpenos, foi caracterizado, correspondendo a $93,38 \%$ dos derivados identificado (Figura 2). Os constituintes encontrados tiveram as estruturas químicas registradas como mostra a Figura 1.

O constituinte mais abundante encontrado nas folhas de Citrus limon foi o limoneno (Tabela 1) assim como descrito na literatura para outras espécies de Citrus (Tu, 2002). Em seguida 
TABELA 1. Rendimento da composição química do óleo essencial extraído das folhas de Citrus limon.

\begin{tabular}{lcc}
\hline \multicolumn{1}{c}{ Constituintes } & Área (\%) & $\begin{array}{c}\text { Índice Kovats } \\
\text { Calculado }\end{array}$ \\
\hline Limoneno & 52,77 & 1025.5 \\
Linalol & 1,73 & 1100 \\
cis-óxido-limoneno & 2,68 & 1129.3 \\
trans-óxido-limoneno & 7,13 & 1133.7 \\
Citronelol & 2,77 & 1150 \\
Neral & 6,85 & 1238.5 \\
Geraniol & 5,49 & 1268.9 \\
Nerol & 4,04 & 1363.3 \\
Acetato de Geraniol & 9,92 & 1384.2 \\
Total & 93,38 & - \\
Rendimento & 0,29 & - \\
\hline
\end{tabular}

obtiveram-se limoneno $(52,77 \%)$, acetato de geraniol $(9,92 \%)$, trans-óxido limoneno $(7,13 \%)$ Neral $(6,85 \%)$, Geraniol $(5,49 \%)$, Nerol $(4,04 \%)$, Citronelol $(2,77 \%)$, cis-óxido limoneno $(2,68 \%)$ e Linalol $(1,73 \%)$. Todos estes compostos são citados na literatura como fazendo parte da constituição química de outras espécies de Citrus (Jahn \& Günzel, 1997; Gonzalez-Molina et al., 2010).

Resultados da análise dos parâmetros hematológicos e bioquímicos de camundongos tratados com óleo essencial de Citrus limon por via oral durante $\mathbf{3 0}$ dias

O óleo essencial de Citrus limon não alterou de forma significativa a massa corpórea dos animais. Durante o tratamento, não foram observados sinais clínicos de toxicidade e nenhuma morte foi registrada. Não houve alteração no consumo
Limoneno (1)<smiles>C=C(C)C1CC=C(C)CC1</smiles>

Neral (4)<smiles>CC(C)=CCC/C(C)=C\C=O</smiles>

Citronelol (7)

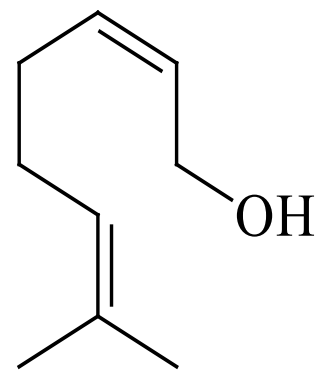

Acetato de geraniol (2)<smiles></smiles>

Geraniol (5)<smiles>CC(C)=CCC/C(C)=C\CO</smiles>

cis-óxido limoneno (8)<smiles>C=C(C)[C@H]1CCC(C)C(=O)C1</smiles>

trans-óxido limoneno (3)<smiles>C=C(C)[C@H]1CCC(C)C(=O)C1</smiles>

Nerol (6)

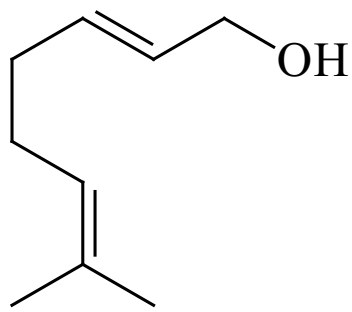

Linalol (9)<smiles>C=CC(C)(O)CCC=C(C)C</smiles>

FIGURA 1. Estrutura química dos constituintes identificados do óleo essencial de Citrus limon. 


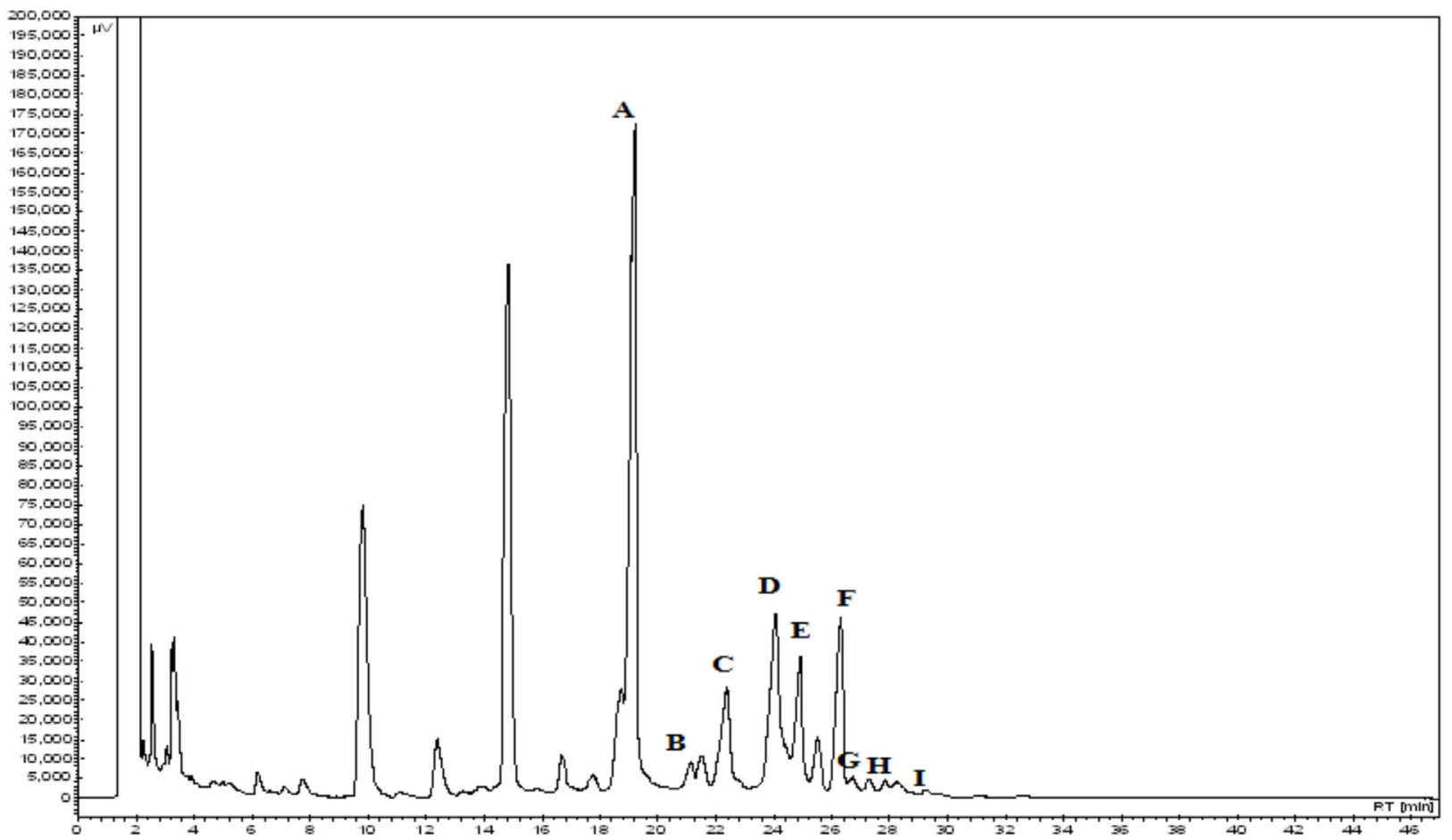

FIGURA 2. Cromatograma do óleo essencial das folhas de Citrus limon obtido em equipamento CG/EM HewlettPackard (Modelo 5971).

de água e ração dos animais (Tabela 2). Nossos resultados são contrários aos efeitos do extrato do fruto, em ratos, que produziu redução do consumo de alimento e do ganho de peso corporal e índice significativo de mortalidade dos animais.

Os resultados mostram que a administração oral por 30 dias com óleo essencial extraído de Citrus limon, de forma geral, não produziu efeitos tóxicos em camundongos Swiss adultos, uma vez que durante o tratamento, nenhum sinal clínico visível de toxicidade foi observado. Em adição, a atividade geral dos camundongos não foi alterada, assim como seu consumo de ração e água.

O acompanhamento da massa corporal do animal é importante indicador para a avaliação da toxicidade de uma substância (latsyno, 1978). O óleo essencial extraído de Citrus limon não alterou o ganho de massa corporal dos camundongos. Nossos resultados estão de acordo com outros estudos realizados com roedores tratados com compostos extraídos de plantas medicinais (Harkness \& Wagner, 1993; Spinella, 2001; Cavalini et al., 2005), os quais também não demonstraram sinais de toxicidade.

TABELA 2. Análise morfológica macroscópica de camundongos Swiss, tratados com óleo essencial de Citrus limon por via oral durante 30 dias.

\begin{tabular}{lcccc}
\hline \multicolumn{1}{c}{ Órgãos } & $\begin{array}{c}\text { Controle } \\
(\mathbf{n}=\mathbf{1 0})\end{array}$ & $\begin{array}{c}\text { OECL 50 } \\
(\mathbf{n}=\mathbf{1 0})\end{array}$ & $\begin{array}{c}\text { OECL 100 } \\
(\mathbf{n}=\mathbf{1 0})\end{array}$ & $\begin{array}{c}\text { OECL 150 } \\
(\mathbf{n}=\mathbf{1 0})\end{array}$ \\
\hline Coração & $0,09 \pm 0,01$ & $0,09 \pm 0,01$ & $0,09 \pm 0,01$ & $0,09 \pm 0,01$ \\
Fígado & $0,81 \pm 0,05$ & $0,79 \pm 0,02$ & $0,80 \pm 0,03$ & $0,81 \pm 0,05$ \\
Baço & $0,06 \pm 0,01$ & $0,06 \pm 0,01$ & $0,06 \pm 0,01$ & $0,06 \pm 0,01$ \\
Rim & $0,09 \pm 0,09$ & $0,09 \pm 0,01$ & $0,09 \pm 0,02$ & $0,09 \pm 0,01$ \\
Cérebro & $0,15 \pm 0,02$ & $0,14 \pm 0,02$ & $0,15 \pm 0,02$ & $0,15 \pm 0,02$ \\
Pulmão & $0,14 \pm 0,01$ & $0,15 \pm 0,02$ & $0,14 \pm 0,01$ & $0,14 \pm 0,01$ \\
Adrenal & $0,005 \pm 0,001$ & $0,004 \pm 0,001$ & $0,005 \pm 0,001$ & $0,005 \pm 0,001$ \\
\hline
\end{tabular}

Legenda: Análise morfológica macroscópica de camundongos machos Swiss, tratados por via oral com solução salina $0,9 \%$ (Controle, $n$ $=10$ ) e com óleo essencial de Citrus limon nas doses $50 \mathrm{mg} \mathrm{kg}^{-1}$ (OECL 50, $\left.n=10\right), 100 \mathrm{mg} \mathrm{kg}^{-1}(\mathrm{OECL} 100, n=10)$ e $150 \mathrm{mg} \mathrm{kg}^{-1}(\mathrm{OECL}$ $150, n=10$ ) durante 30 dias. Os valores representam a média + E.P.M. dos valores expressos em termos de massa relativa $\mathrm{g}^{100 \mathrm{~g}^{-1}} \mathrm{do}$ número de animais usados nos experimentos. $\mathrm{n}$ - representa o número de animais em cada grupo. As vísceras foram cuidadosamente removidas após a eutanásia por aprofundamento de anestesia etéria. Em seguida, dissecadas e determinada suas massas úmidas em balança analítica. ${ }^{a} p<0,05$, quando comparados ao grupo controle (ANOVA e teste t de Student-Newman-Keuls como post hoc test);

Rev. Bras. Pl. Med., Campinas, v.15, n.4, supl.I, p.708-716, 2013. 
O tratamento crônico com óleo essencial extraído de Citrus limon em camundongos nas doses de 50 e $100 \mathrm{mg} \mathrm{kg}^{-1}$, de forma geral, não induziu modificações no perfil bioquímico (Tabela 3). Entretanto, os camundongos tratados com a dose de $150 \mathrm{mg} \mathrm{kg}^{-1}$ do óleo essencial extraído de Citrus limon apresentaram a maioria dos parâmetros dentro da faixa de referência (Vijayalakshmi et al., 2000) exceto para o valor da uréia, ácido úrico, triglicerídeos no grupo tratado com a maior dose, os quais diminuíram de forma significativa em 21 , 11 e $8 \%$ quando comparados ao grupo controle, respectivamente $(p<0,05)$, assim, como a AST que reduziu, respectivamente, em $9 \%(p<0,05)$, no grupo tratado com óleo essencial extraído de Citrus limon em relação ao grupo controle (Tabela 3). Quando comparados os grupos controle e os grupos tratados com o óleo essencial extraído de Citrus limon com grupo tratado somente com Tween 80 0,5\% não foram observadas mudanças significativas em nenhum dos parâmetros bioquímicos.

De fato, resultados do nosso laboratório (dados não apresentados) mostram que o óleo essencial extraído de Citrus limon nas doses de até $150 \mathrm{mg} \mathrm{kg}^{-1}$ por via oral não produziram morte em camundongos de ambos os sexos, por período de observação de até 30 dias. Embora de um modo geral o perfil bioquímico dos animais estivesse dentro dos valores de referência, (Doyama et al., 2005) houve exceções para a uréia, ácido úrico, triglicerídeos e AST. A alteração significativa verificada nos níveis plasmáticos de uréia e ácido úrico apenas no grupo tratado com a dose de $150 \mathrm{mg}$ $\mathrm{kg}^{-1}$ do óleo essencial extraído de Citrus limon pode ser inicialmente interpretada como uma alteração renal. A redução nos níveis plasmáticos de uréia e ácido úrico fornece indícios de uma melhora da função renal, sugerindo o seu uso no tratamento da insuficiência renal aguda ou, ainda, pode indicar uma diminuição do catabolismo protéico (Dantas et al., 2006).

Com relação aos níveis séricos dos triglicerídeos foi detectada uma diminuição significativa nos camundongos tratados com a dose de $150 \mathrm{mg} \mathrm{kg}^{-1}$ do óleo essencial extraído de Citrus limon. Os dados da literatura para os valores de triglicerídeos (Tabela 3) são inferiores aos encontrados (Martin et al., 1981; Doyama et al., 2005; Dantas et al., 2006). Diante dos efeitos na redução sérica dos triglicerídeos pode ser sugerido o uso do o óleo essencial extraído de Citrus limon no tratamento das dislipidemias.

As análises das enzimas aminotransferases séricas (ALT e AST) e da fosfatase alcalina são importantes indicadores de lesões nas células hepáticas (Wright \& Plummer, 1974). Uma droga não provoca dano algum no fígado sem interferir com a atividade normal dessas enzimas (Vijayalakshmi et al., 2000). A fosfatase alcalina é um marcador importante da atividade da membrana plasmática

TABELA 3. Parâmetros bioquímicos obtidos do soro de camundongos Swiss, tratados com óleo essencial de Citrus limon por via oral durante 30 dias.

\begin{tabular}{lcccc}
\hline \multicolumn{1}{c}{ Parâmetros } & $\begin{array}{c}\text { Controle } \\
(\mathbf{n}=10)\end{array}$ & $\begin{array}{c}\text { OECL 50 } \\
(\mathbf{n}=1 \mathbf{0})\end{array}$ & $\begin{array}{c}\text { OECL 100 } \\
(\mathbf{n}=10)\end{array}$ & $\begin{array}{c}\text { OECL 150 } \\
(\mathbf{n}=10)\end{array}$ \\
\hline Glicose $\left(\mathrm{mg} \mathrm{dL}^{-1}\right)$ & $88,74 \pm 8,10$ & $88,03 \pm 8,06$ & $88,25 \pm 8,05$ & $88,32 \pm 8,04$ \\
Uréia $\left(\mathrm{mg} \mathrm{dL}^{-1}\right)$ & $54,67 \pm 0,22$ & $54,37 \pm 0,19$ & $54,23 \pm 0,03$ & $43,32 \pm 0,04^{\mathrm{a}}$ \\
Creatinina $\left(\mathrm{mg} \mathrm{dL}^{-1}\right)$ & $0,36 \pm 0,01$ & $0,37 \pm 0,02$ & $0,35 \pm 0,01$ & $0,33 \pm 0,02$ \\
Ácido úrico $\left(\mathrm{mg} \mathrm{dL}^{-1}\right)$ & $2,61 \pm 0,04$ & $2,68 \pm 0,17$ & $2,69 \pm 0,02$ & $2,32 \pm 0,04^{\mathrm{a}}$ \\
Triglicerídeos $\left(\mathrm{mg} \mathrm{dL}^{-1}\right)$ & $106,7 \pm 0,05$ & $105,10 \pm 0,13$ & $105,67 \pm 1,28$ & $98,12 \pm 0,49^{\mathrm{a}}$ \\
CT $\left(\mathrm{mg} \mathrm{dL}^{-1}\right)$ & $86,07 \pm 0,57$ & $86,09 \pm 0,24$ & $86,05 \pm 0,68$ & $86,02 \pm 0,82$ \\
Proteínas totais $\left(\mathrm{mg} \mathrm{dL}^{-1}\right)$ & $6,64 \pm 1,03$ & $6,28 \pm 0,92$ & $6,23 \pm 0,94$ & $6,32 \pm 0,84$ \\
AST $(\mathrm{U} \mathrm{mL-1})$ & $91,40 \pm 1,81$ & $91,71 \pm 0,73$ & $92,91 \pm 0,21$ & $82,82 \pm 0,38^{\mathrm{a}}$ \\
ALT $\left(\mathrm{U} \mathrm{mL} \mathrm{mL}^{-1}\right)$ & $57,83 \pm 0,81$ & $58,27 \pm 0,11$ & $57,29 \pm 0,07$ & $58,35 \pm 0,04$ \\
Fosfatase alcalina $\left(\mathrm{U} \mathrm{l}^{-1}\right)$ & $157,6 \pm 0,97$ & $158,2 \pm 0,09$ & $157,4 \pm 0,17$ & $158,3 \pm 0,04$ \\
Bilirrubina total $\left(\mathrm{mg} \mathrm{dL}^{-1}\right)$ & $0,16 \pm 0,02$ & $0,16 \pm 0,04$ & $0,16 \pm 0,01$ & $0,16 \pm 0,03$ \\
Bilirrubina direta $\left(\mathrm{mg} \mathrm{dL}^{-1}\right)$ & $0,12 \pm 0,02$ & $0,12 \pm 0,01$ & $0,12 \pm 0,01$ & $0,12 \pm 0,02$ \\
\hline
\end{tabular}

Legenda: Parâmetros bioquímicos obtidos do soro de camundongos machos Swiss, tratados por via oral com solução salina 0,9\% (Controle, $n=10$ ) e com óleo essencial de Citrus limmon (OECL) nas doses $50 \mathrm{mg} \mathrm{kg}^{-1}$ (OECL 50, $n=10$ ), $100 \mathrm{mg} \mathrm{kg}^{-1}$ (OECL 100, $\left.n=10\right)$ e 150 mg

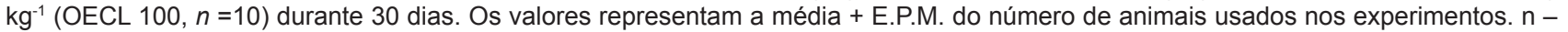
representa o número de animais em cada grupo. ${ }^{a} p<0,05$, quando comparados ao grupo controle (ANOVA e teste t de Student-NewmanKeuls como post hoc test);

Rev. Bras. PI. Med., Campinas, v.15, n.4, supl.I, p.708-716, 2013. 
e do retículo endoplasmático (Martin et al., 1981)e muitas vezes são usadas para avaliar a integridade da membrana (Akanji et al., 1993). A diminuição nos níveis plasmáticos de AST observado neste estudo, além de ser estatisticamente significante em relação ao grupo controle, foi maior que os níveis de referência para roedores (Coimbra et al., 1955; Mitruka \& Ramsley, 1977). Estes dados não fornecem indícios de alterações na função hepática como proposto por Kaneko et al. (1997). Os níveis séricos de ALT aumentam quando ocorrem alterações na permeabilidade ou injúria nos hepatócitos. AAST tem uma isoenzima mitocondrial e não é liberada tão rapidamente quanto a ALT, que é essencialmente citoplasmática. Isto pode justificar o fato de ter-se registrado alterações significativas apenas nos níveis de AST. Além disso, a ALT é um indicador mais sensível de hepatotoxicidade aguda do que a AST, uma vez enquanto a primeira é essencialmente hepática, a segunda também pode ser encontrada em concentrações elevadas em outros órgãos, como rins, pulmões e coração (Al-Habori et al., 2002).

De maneira semelhante, observou-se que o tratamento oral dos animais com o óleo essencial extraído de Citrus limon não alterou significativamente o perfil hematológico (Tabela 4), embora tenham sido observadas mudanças nos leucócitos totais, neutrófilos, eosinófilos, linfócitos e monócitos. A contagem diferencial de neutrófilos, linfócitos, eosinófilos e monócitos revelou pequenas flutuações, embora, dentro dos limites de referência (Harkness \& Wagner, 1993) e sem indicativo de importância clínica. Quando comparados os grupos controle e tratados com o óleo essencial extraído de Citrus limon com grupo tratado com Tween 80 0,5\% não foram observadas mudanças significativas em nenhum dos parâmetros hematológicos.

\section{CONCLUSÃO}

A extração do óleo essencial de Citrus limon resultou na identificação exclusiva de monoterpenos. Baseados nos resultados obtidos a partir dos estudos hematológicos e bioquímicos do sangue dos camundongos adultos, conclui-se que a administração crônica do óleo essencial de Citrus limon não produz efeitos tóxicos sobre a maioria dos parâmetros bioquímicos e hematológicos estudados de camundongos Swiss adultos. Entretanto, diminuição dos níveis séricos de uréia e ácido úrico em camundongos tratados com a maior dose do óleo essencial de Citrus limon aponta para uma possível melhora da função renal, bem como, a redução dos níveis de triglicerídeos sugerem o uso no tratamento das dislipidemias. No entanto, aumento dos níveis de AST em camundongos tratados com o óleo essencial de Citrus limon na mesma dose sugere para possível sobrecarga da função hepática. Além disso, nossos resultados sugerem para possível uso deste óleo no tratamento das dislipidemias. Dessa forma, os efeitos farmacológicos e toxicológicos do óleo essencial de Citrus limon precisam ser investigados de forma mais detalhada.

AGRADECIMENTO financeiro.

TABELA 4. Parâmetros hematológicos de camundongos Swiss, tratados com óleo essencial de Citrus limmon por via oral durante 30 dias.

\begin{tabular}{lcccc}
\hline \multicolumn{1}{c}{ Parâmetros } & $\begin{array}{c}\text { Controle } \\
(\mathbf{n = 1 0})\end{array}$ & $\begin{array}{c}\text { OECL 50 } \\
(\mathbf{n = 1 0})\end{array}$ & $\begin{array}{c}\text { OECL 100 } \\
(\mathbf{n = 1 0})\end{array}$ & $\begin{array}{c}\text { OECL 150 } \\
(\mathbf{n = 1 0})\end{array}$ \\
\hline Hemácias $\left(\mathrm{mm}^{3}\right)$ & $8,64 \pm 0,03$ & $8,68 \pm 0,02$ & $8,60 \pm 0,01$ & $8,61 \pm 0,04$ \\
Hemoglobina $\left(\mathrm{g} \mathrm{dL}^{-1}\right)$ & $14,37 \pm 0,15$ & $14,36 \pm 0,09$ & $14,33 \pm 0,03$ & $14,35 \pm 0,04$ \\
Hematócrito (\%) & $44,15 \pm 0,30$ & $44,11 \pm 0,13$ & $44,16 \pm 0,33$ & $44,32 \pm 0,04$ \\
VCM (fL) & $49,67 \pm 0,04$ & $49,61 \pm 0,51$ & $49,55 \pm 0,05$ & $49,62 \pm 0,04$ \\
HCM (pg) & $16,64 \pm 0,03$ & $16,68 \pm 0,11$ & $16,63 \pm 0,32$ & $16,62 \pm 0,49$ \\
CHCM (g dL $\left.{ }^{-1}\right)$ & $36,50 \pm 0,14$ & $36,86 \pm 0,36$ & $36,17 \pm 0,45$ & $36,12 \pm 0,45$ \\
RDW (\%) & $13,67 \pm 0,04$ & $13,29 \pm 0,11$ & $13,51 \pm 0,02$ & $13,52 \pm 0,04$ \\
Plaquetas (mm $\left.{ }^{3}\right)$ & $292,40 \pm 0,83$ & $294,7 \pm 2.28$ & $292,90 \pm 0,21$ & $291,8 \pm 1,75$ \\
Leucócitos totais $\left(\mathrm{mm}^{3}\right)$ & $8,63 \pm 0,03$ & $8,60 \pm 0,08$ & $8,69 \pm 0,06$ & $8,44 \pm 0,04^{\mathrm{a}}$ \\
Neutrófilos (\%) & $18,66 \pm 0,04$ & $18,67 \pm 0,09$ & $18,63 \pm 0,09$ & $18,15 \pm 0,04^{\mathrm{a}}$ \\
Eosinófilos (\%) & $0,36 \pm 0,02$ & $0,37 \pm 0,04$ & $0,38 \pm 0,05$ & $0,31 \pm 0,03^{\mathrm{a}}$ \\
Linfócitos (\%) & $78,12 \pm 0,31$ & $78,41 \pm 0,28$ & $78,17 \pm 0,15$ & $74,33 \pm 0,26^{\mathrm{a}}$ \\
\hline
\end{tabular}

Legenda: Parâmetros hematológicos obtidos de camundongos machos Swiss, tratados por via oral com solução salina $0,9 \%$ (Controle, $n=10$ ) e com óleo essencial de Citrus limmon (OECL) nas doses $50 \mathrm{mg} \mathrm{kg}^{-1}$ (OECL 50, $\left.n=10\right), 100 \mathrm{mg} \mathrm{kg}^{-1}$ (OECL 100, $\left.n=10\right)$ e $150 \mathrm{mg}$ $\mathrm{kg}^{-1}(\mathrm{OECL} 100, n=10)$ durante 30 dias. Os valores representam a média + E.P.M. do número de animais usados nos experimentos. $\mathrm{n}-$ representa o número de animais em cada grupo. ${ }^{a} p<0,05$, quando comparados ao grupo controle (ANOVA e teste t de Student-NewmanKeuls como post hoc test);

Rev. Bras. Pl. Med., Campinas, v.15, n.4, supl.I, p.708-716, 2013. 


\section{REFERÊNCIA}

ADAMS, R.P. Identification of essential oil components by gas chromatography/quadrupole mass epectroscopy. Carol Stream, Illinois, USA: Allured Publishing Corporation, 2001. 456p.

AGRA, M.F. et al. Synopsis of the plants known as medicinal and poisonous in Northeast of Brazil. Revista Brasileira de Farmacognosia, v.17, n.1, p.114-40, 2007.

AKANJI, M.A. et al. Effect of chronic consumption of metabisulphite the integrity of the kidney cellular system. Toxicology, v.81, n.3, p.173-9, 1993.

AL-HABORI, M. et al. Toxicological evaluation of Catha edulis leaves: a long term feeding experiment in animals. Journal of Ethnopharmacology, v.83, n.3, p.209-17, 2002.

ALENCAR, J.W. et al. Kovats indices as a preselection routine in mass spectra library search of volatiles. Journal of Natural Product, v.47, n.5, p.890-2,1984.

ALENCAR, J.W. et al. Kovats índices simulation in essencial oil analysis. Quimica. Nova, v.13, n.4, p.282-4,1990.

ARRIAGA, E.J.; RUMBERO, A. Naringin, hesperidin and neohesperidin content in juices from thirteen Citrus spp. Fitoterapia, v.51, p.31-6, 1990.

BRUNETON, J. Pharmacognosie, phytochimie, plantes medicinales. 2.ed. Paris: Lavoisier, 1993. 1120p.

CACERES, A. et al. Screening of antimicrobial activity of plants popularly used in Guatemala for the treatment of dermatomucosal diseases. Journal of Ethnopharmacology, v.20, n.3, p. 223-37, 1987.

CALAPAI, G. et al. Antiobesity and cardiovascular toxic effects of Citrus aurantium extracts in the rat: a preliminary report. Fitoterapia, v.70, n.6, p.586-92, 1999.

CARVALHO-FREITAS, M.I.R.; COSTA, M. Anxiolitic and sedative effects of extracts and essential oil from Citrus aurantium. Biological \& Pharmaceutical Bulletin, v.25, n.12, p.1629-33, 2002.

CAVALINI, M. Serviço de informações sobre plantas medicinais e medicamentos fitoterápicos. Revista Eletrônica de Extensão, v.2, n.1, p.2-11, 2005.

COIMBRA, I.K.S. et al. Perfil bioquímico sérico de provas funcionais hepática e renal após intoxicação experimental com extratos aquosos de folhas de Melia azedarach L. em ratos albinos (Rattus norvegicus). Revista Brasileira de Toxicologia, v.8, p.258-64, 1955.

DANTAS, J.A. et al. Valores de referência de alguns parâmetros fisiológicos de ratos do Biotério Central da Universidade Estadual de Maringá, Estado do Paraná. Acta Scientiarum Health Sciences, v.28, n.2, p.165-70, 2006.

DE FEO, R. et al. Traditional phytotherapy in the Peninsula Sorrentina, Campania, Southern Italy. Journal of Ethopharmacology, v.36, n.2, p.113-25, 1992.

DOYAMA, J.T. et al. Chemical investigation and effects of the tea of Passiflora alata on biochemical parameters in rats. Journal of Ethnopharmacology, v.96, n.3, p.371-4, 2005.

FENNER, R. et al. Plantas utilizadas na medicina popular brasileira com potencial atividade antifúngica. Revista
Brasileira de Ciências Farmacêuticas, v.42, n.3, p.369-94, 2006.

FOSTER, H.B. et al. Antispasmodic effects of some medicinal plants. Planta Medica, v.40, n.4, p.309-19, 1980.

GONZALEZ-MOLINA, E. et al. Natural bioactive compounds of Citrus limon for food and health. Journal of Pharmaceutical and Biomedical Analysis, v.51, n.2, p.327-45, 2010.

GRAY, A.M.; FLATT, P.R. Nature's own pharmacy: the diabetes perspective. Proceedings of the Nutrition Society, v.56, n.1B, p.507-17, 1997.

HARKNESS, S.E.; WAGNER, J.E. Biologia e clínica de coelhos roedores. São Paulo: Livraria Roca, 1993. $238 p$.

HUANG, Y. et al. Fructus aurantii reduced portal pressure in portal hypertensive rats. Life Sciences, v.57, n.22, p.2011-20, 1995.

HYUN, K.D. et al. Inhibitory effect of herbal medicines on rotavirus infectivity. Biological \& Pharmaceutical Bulletin, v.23, n.3, p.356-8, 2000.

IATSYNO, A.I. et al. Pharmacology of Calenduloside B - A new terpene glycoside obtained from the roots of Calendula officinalis. Farmakologiia i toksikologiia, v.41, p.550-60, 1978.

JAHN, A.I.; GÜNZEL, P.K.H. The value of spermatology in male reproductive toxicology: do spermatologic examinations in fertility studies provide new and additional information relevant for safety assessment? Reproductive Toxicology, v.11, n.2-3, p.171-8, 1997.

KANEKO, J.J. Clinical biochemistry of domestic animals. San Diego: Academic Press, 1997. 293-4p.

KUSTER, R.M.; ROCHA, L.M. Cumarinas, cromonas e xantonas. In: SIMÕES, C.M.O et al. Farmacognosia: da planta ao medicamento. 5.ed. Porto Alegre/ Florianópolis: Editora da UFRGS/Editora da UFSC, 2003. p.537-56.

LIEBSTEIN, A.M. Therapeutic effects of various food articles. American Medicine, v.33, p.33-8, 1927.

MARTIN, D.W. et al. In: HARPER'S Review of Biochemistry. Califórnia: Lange Medical, 1981. 688p.

MATOS, F.J.A. et al. Essential oil of Mentha $x$ villosa Huds. from Northeastern Brazil. Journal of Essential Oil Research, v.11, p.41-4, 1999.

MELO, M.F.F.; ZICKEL, C.S. Os gêneros Zanthoxylum L. e Esenbeckia Kunth (Rutaceae) no Estado de Pernambuco, Brasil. Acta Botânica Brasileira, v.18, n.1, p.73-90, 2004.

MITRUKA, B.M.; RAMSLEY, H.M. Clinical biochemical and hematological reference values in normal experimental animals. New York: Masson Publishing, 1977. 96p.

PENIDON, A.B.; SILVA, M.W.B. Guia Fitoterápico. Facimp, 2007. 11-14p.

REZENDE, H.A.; COCCO, M.I.M. A utilização de fitoterapia no cotidiano de uma população rural. Revista da Escola de Enfermagem da USP, v.36, n.3, p.282-8, 2002.

SPINELLA, M. Psycopharmacology of herbal medicine: plants that alter mind, brain, and behavior, Massachussets: The MIT, 2001. 578p.

TU, N.T. et al. Volatile constituents of Vietnamese pummelo, orange, tangerine and peels oils. Flavour and Fragrance Journal, v.17, n.3, p.169-74, 2002. 
VENDRUSCOLO, G.S. et al.. Dados químicos e farmacológicos sobre as plantas utilizadas como medicinais pela comunidade do bairro Ponta Grossa, Porto Alegre, Rio Grande do Sul. Revista Brasileira de Farmacognosia, v.15, n.4, p.361-72, 2005.

VIEIRA, L.S. Fitoterapia da Amazônia. Manual de plantas medicinais. A farmácia de Deus. 2.ed. São Paulo: Agronômica Ceres, 1992. 347p.

VIJAYALAKSHMI, T. et al. Toxic studies on biochemical parameters carried out in rats with Serankottai nei, a siddha drug-milk extract of Semecarpus anacardium nut. Journal of Ethnopharmacology, v. 69, n.1, p.9-15, 2000.

WAYNFORTH, B.H. Injection techniques. In: experimental and Surgical Techniques in the Rat. London: Academic Press, 1980.

WRIGHT, P.J.; PLUMMER, D.T. The use of urinary enzyme measurement of direct renal damage caused by nephrotoxic compound. Biochemical Pharmacology, v.23, p.65-73, 1974. 